\title{
Interrogating pollution sources in a mangrove food web using multiple stable isotopes
}

\author{
Iara da C. Souza a , Hiulana P. Arrivabene ${ }^{\mathrm{b}}$, Carol-Ann Craig ${ }^{\mathrm{c}}$, Andrew J. Midwood ${ }^{\mathrm{c}, 1}$, Barry Thornton ${ }^{\mathrm{c}}$, \\ Silvia T. Matsumoto ${ }^{\mathrm{d}}$, Michael Elliott ${ }^{\mathrm{e}}$, Daniel A. Wunderlin ${ }^{\mathrm{f}, *}$, \\ Magdalena V. Monferrán ${ }^{\mathrm{f}}$, Marisa N. Fernandes ${ }^{\mathrm{a}, *}$ \\ a Universidade Federal de São Carlos (UFSCar), Centro de Ciências Biológicas e da Saúde, Departamento de Ciências Fisiológicas, PO box 676, 13565-905 São Carlos, São Paulo, Brazil \\ ${ }^{\mathrm{b}}$ Universidade Estadual Paulista Júlio de Mesquita Filho (UNESP), Instituto de Biociências de Botucatu, Departamento de Botânica, 18618-970, P.0. Box 510, Botucatu, São Paulo, Brazil \\ c James Hutton Institute, Craigiebuckler, Aberdeen AB15 8QH, Scotland, UK \\ d Universidade Federal do Espírito Santo (UFES), Centro de Ciências Humanas e Naturais, Departamento de Ciências Biológicas, 29075-910 Vitória, Espírito Santo, Brazil \\ e University of Hull, Institute of Estuarine E' Coastal Studies (IECS), Hull HU6 7RX, UK

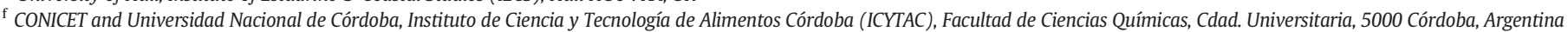

\section{H I G H L I G H T S}

$\overline{-} \delta^{15} \mathrm{~N}$ was higher throughout a food web at the site with higher anthropogenic pressure.

- $\delta^{15} \mathrm{~N}$ suggests mangrove plants can be a biomarker for anthropogenic pollution.

- Sr ratio showed a greater influence of marine water in the studied estuaries.

- $\mathrm{Pb}$ isotope ratios suggest metal pollution is influenced by metallurgical activities.

- Mangrove plants are affected by anthropospheric particulate matter.

\section{A R T I C L E I N F O}

\section{Article history:}

Received 13 April 2018

Received in revised form 23 May 2018

Accepted 24 May 2018

Available online 1 June 2018

Editor: Jay Gan

\section{Keywords:}

Food web

Trophic chain

Neotropical mangroves

Metallurgic pollution

\section{G R A P H I C A L A B S T R A C T}

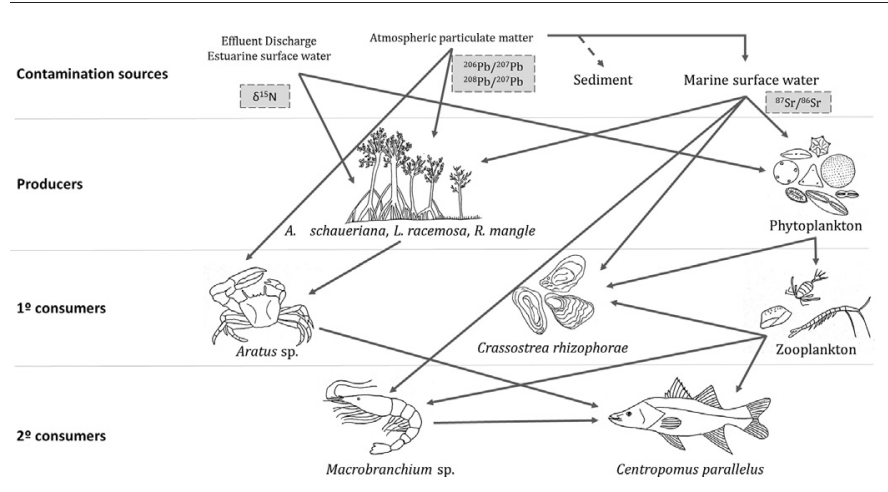

\section{A B S T R A C T}

Anthropogenic activities including metal contamination create well-known problems in coastal mangrove ecosystems but understanding and linking specific pollution sources to distinct trophic levels within these environments is challenging. This study evaluated anthropogenic impacts on two contrasting mangrove food webs, by using stable isotopes $\left(\delta^{13} \mathrm{C}, \delta^{15} \mathrm{~N},{ }^{87} \mathrm{Sr} /{ }^{86} \mathrm{Sr},{ }^{206} \mathrm{~Pb} /{ }^{207} \mathrm{~Pb}\right.$ and $\left.{ }^{208} \mathrm{~Pb} /{ }^{207} \mathrm{~Pb}\right)$ measured in sediments, mangrove trees (Rhizophora mangle, Laguncularia racemosa, Avicennia schaueriana), plankton, shrimps (Macrobranchium sp.), crabs (Aratus sp.), oysters (Crassostrea rhizophorae) and fish (Centropomus parallelus) from both areas. Strontium and $\mathrm{Pb}$ isotopes were also analysed in water and atmospheric particulate matter $(\mathrm{PM}) . \delta^{15} \mathrm{~N}$ indicated that crab, shrimp and oyster are at intermediate levels within the local food web and fish, in this case C. parallelus, was confirmed at the highest trophic level. $\delta^{15} \mathrm{~N}$ also indicates different anthropogenic pressures between both estuaries; Vitória Bay, close to intensive human activities, showed higher $\delta^{15} \mathrm{~N}$ across the food web, apparently influenced by sewage. The ratio ${ }^{87} \mathrm{Sr} /{ }^{86} \mathrm{Sr}$ showed the primary influence of marine water throughout the entire food web. $\mathrm{Pb}$ isotope ratios suggest that PM is primarily influenced by metallurgical activities, with some secondary influence on mangrove plants and crabs sampled in the area adjacent to the smelting works. To our knowledge, this is the first demonstration of the effect of anthropogenic pollution (probable sewage pollution) on the isotopic

\footnotetext{
* Corresponding authors.

E-mail addresses: dwunder@fcq.unc.edu.ar (D.A. Wunderlin), dmnf@ufscar.br (M.N. Fernandes).

${ }^{1}$ Current address: University of British Columbia, Department of Biology, Okanagan Kelowna, V1V 1V7 B.C., Canada.
} 
fingerprint of estuarine-mangrove systems located close to a city compared to less impacted estuarine mangroves. The influence of industrial metallurgical activity detected using $\mathrm{Pb}$ isotopic analysis of PM and mangrove plants close to such an impacted area is also notable and illustrates the value of isotopic analysis in tracing the impact and species affected by atmospheric pollution.

(C) 2018 Elsevier B.V. All rights reserved.

\section{Introduction}

An estuary is a semi closed water body connecting freshwater with the sea and having influence from both environments; the essence of understanding estuarine processes is connectivity which determines whether the areas are sinks for contaminants (Potter et al., 2010; Wolanski and Elliott, 2015). Connectivity exposes the estuaries to many pressures from both urbanisation and industrialisation, directly or indirectly (Elliott and Whitfield, 2011). Among those pressures, metal contamination in tropical areas is a serious problem for mangrove ecosystems given that sewage and industrial contaminants carried by rivers and other contamination sources, derived from coastal engineering work, affect the health status of estuarine environments (Hogarth, 1999).

Estuarine mangrove ecosystems have their biota influenced by several physical and chemical changes (i.e. salinity, sea level, organic matter) over which are superimposed the ecological structure and interactions. In turn, these characteristics influence the bioavailability of metal/metalloids in the aquatic ecosystem and favour their transfer from the lower to the higher trophic levels throughout the food web (Kulkarni et al., 2018; Lewis et al., 2011; Wolanski and Elliott, 2015). Such a trophic transfer may reach humans, particularly those who consume fish frequently (Jiang et al., 2010). However, trophic transfer is unlikely to be the only pathway for toxic metals/metalloids input in estuarine biota and is dependent on other human activities in the surrounding area which may also introduce such toxic elements into the estuarine ecosystem and its components, including mangrove, plankton, fish, etc.

While the contamination of estuarine environments by trace metals has long been of concern (McLusky and Elliott, 2004), there is poor information on flux rates through such systems, and on the processes governing the fate and effects of the trace metals (Luoma and Rainbow, 2008). In the southeast coast of Brazil, the environment of the State of Espírito Santo has long been negatively impacted by industrial metallurgy, including mining complexes, steel and smelting industries. Two estuaries from this area (Santa Cruz and Vitória Bay) have diverse environmental aerial contamination from metallic smoke particles (Arrivabene et al., 2015), and surface water contamination with Fe, $\mathrm{Pb}, \mathrm{As}, \mathrm{Hg}, \mathrm{Cr}$ and $\mathrm{Cu}$, which was correlated with metal/metalloid accumulation in Centropomus parallelus (fish) muscle (Souza et al., 2013). Metal accumulation has been detected in different species of mangrove plants, such as Laguncularia racemosa (Souza et al., 2014a), Rhizophora mangle (Souza et al., 2014b) and Avicennia schaueriana (Souza et al., 2015). However, these studies did not establish either the pollution source or the probable pollutant pathway and transport through the estuarine mangrove food web. Moreover, the estuarine mangrove ecosystems close to the industrial and domestic activities areas (Vitória Bay) were more affected than those located further north and away from the main pollution sources (Santa Cruz) (Arrivabene et al., 2015; Souza et al., 2013, 2014a, 2014b, 2015).

The presence of toxic elements in the food web depends on more than one factor and contamination of the surface water, sediment or particulate matter, can affect the ecosystem structure and its trophic relationships (Bayen, 2012; Laws, 1993). When contaminants are transported through the food web, the analysis of stable isotopes, such as carbon $\left(\delta^{13} \mathrm{C}\right)$ and nitrogen $\left(\delta^{15} \mathrm{~N}\right)$ is a valuable tool to establish trophic levels and their contamination (Bond, 2010). $\delta^{13} \mathrm{C}$ is a valuable marker for identifying different primary producers, while $\delta^{15} \mathrm{~N}$ is effective for assessing the trophic position, given that enrichment of the heavy nitrogen isotope occurs incrementally and with a constant rate (3-4\%) across trophic levels (Hobson et al., 2002).

As metal/metalloid contamination can originate from several sources, stable isotope ratios have been used to identify the origin (source) of metals and metalloids in the food web (Ikemoto et al., 2008; Peterson and Fry, 1987; Podio et al., 2013). For instance, the strontium isotopic ratio $\left({ }^{87} \mathrm{Sr} /{ }^{86} \mathrm{Sr}\right)$ is relatively constant in marine environments, while it changes with the geology and other land mass factors. Thus, ${ }^{87} \mathrm{Sr} /{ }^{86} \mathrm{Sr}$ can primarily reflects the bedrock geology of the neighbour continent, when the estuary is dominated by freshwater inputs. Conversely, the ${ }^{87} \mathrm{Sr} /{ }^{86} \mathrm{Sr}$ show values close to those for the marine environment which indicates that the estuary is dominated by seawater input, with little or no influence from land-based sources. Hence, the contamination in the estuary can be associated with either continental or marine inputs. Moreover, the lead isotopes ratios $\left({ }^{206} \mathrm{~Pb} /{ }^{207} \mathrm{~Pb}\right.$ and ${ }^{208} \mathrm{~Pb} /{ }^{207} \mathrm{~Pb}$ ) have been used as anthropogenic tracers (Chow et al. 1973, 1975; Chow and Earl, 1970, 1972; Chow and Johnstone, 1965) and are used as 'fingerprints' of environmental pollution (Cheng and Hu, 2010; Komárek et al., 2008).

The use of stable isotopes to assess the sources of environmental pollution has increased in recent years (Négrel et al., 2012) and there are frequent studies using single volatile stable isotopes $\left(\delta^{2} \mathrm{H}, \delta^{13} \mathrm{C}, \delta^{15} \mathrm{~N}\right.$, $\delta^{18} \mathrm{O}, \delta^{34} \mathrm{~S}$ ) (e.g. Griboff et al., 2018; Monferrán et al., 2016), and occasionally combined ones (e.g. $\delta^{2} \mathrm{H}$ and $\delta^{18} \mathrm{O}$ for the evaluation of pollutant plumes in groundwater) (Negrel et al., 2017). The use of non-volatile stable isotopes $(\mathrm{Pb}, \mathrm{Sr}, \mathrm{Hg}$, etc. signatures) is less frequent (Négrel et al., 2012; Négrel and Petelet-Giraud, 2012). Furthermore, the combined use of both volatile and non-volatile environmental stable isotopes is uncommon (Négrel et al., 2012), despite this combined use being valuable to distinguish the origin of food products (e.g. Baroni et al., 2015), which is a challenge similar to finding the source of an environmental contaminant.

Therefore, the main goal of this study was to assess differences in the behaviour of stable isotopes between two estuaries affected by different anthropogenic pressures, establishing new endpoints to verify the negative impact of both urban and industrial activities on aquatic ecosystems. We hypothesised that the evaluation of multiple stable isotopes in both mangrove ecosystems (Vitória Bay and /santa Cruz), and in the Tubarão (industrial) Complex (Vitória Bay), will allow linking the anthropogenic activity to different levels and sources of contamination in both estuaries. In turn this provides a valuable tool-kit for the evaluation of other estuarine mangrove systems affected by anthropogenic and industrial pollution worldwide.

\section{Material and methods}

\subsection{Sampling areas}

This study was conducted in two mangrove areas located in the state of Espírito Santo, Brazil: Vitória Bay and Santa Cruz, which are 10 and $70 \mathrm{~km}$, respectively, from the industrial Tubarão Complex (Fig. 1). Sampling was carried out in March 2015, the end of the summer period in the southern hemisphere.

The mangrove ecosystem in Santa Cruz $\left(19^{\circ} 56^{\prime} 26.2^{\prime \prime} \mathrm{S}\right.$ and $40^{\circ} 12^{\prime}$ $87.0^{\prime \prime} \mathrm{W}$ ) covers approximately $12 \mathrm{~km}^{2}$, it is formed by two rivers, being part of the 'Piraquê-Açu' and 'Piraquê-Mirim' Mangrove Ecological Reserve. There is an extensive and well-preserved mangrove area, 


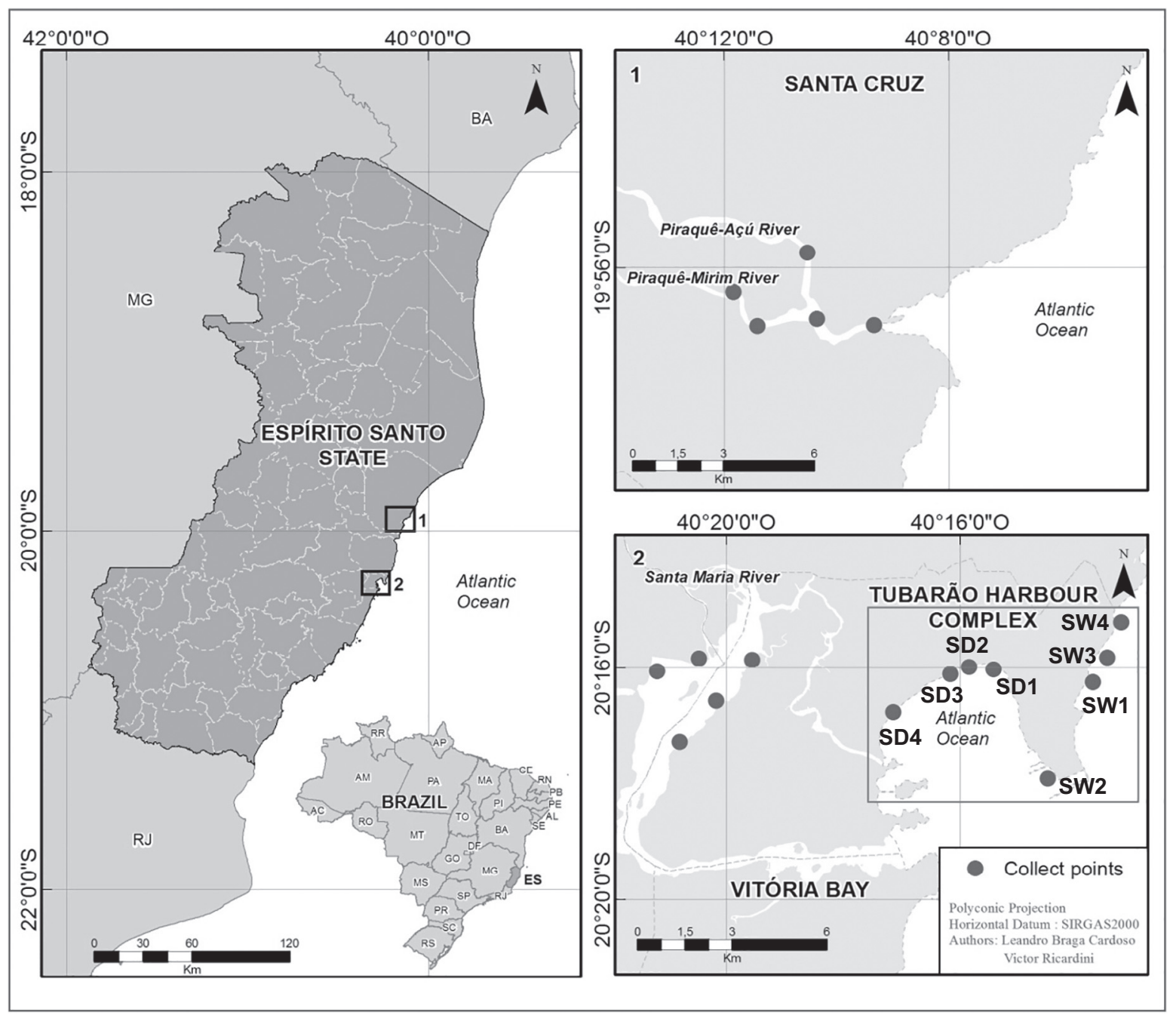

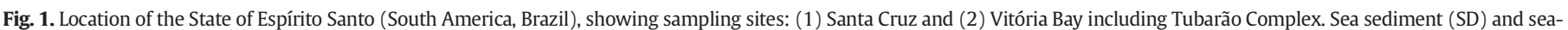
water (SW) sample sites in Tubarão complex are shown in (2).

far from the industries of the Tubarão Complex as the source of metal contamination (Fig. 1).

Vitória Bay $\left(20^{\circ} 14^{\prime} 31.5^{\prime \prime} \mathrm{S}\right.$ and $\left.40^{\circ} 19^{\prime} 84.7^{\prime \prime} \mathrm{W}\right)$ is an estuarine complex formed by five rivers. It was originally an archipelago formed from 54 islands, which, after several land-claim projects, resulted in the present 14 islands. Land-claim occurred between 1830 and 1996, totalling $1.2 \mathrm{~km}^{2}$, of which half of this area was composed of mangroves. Salt marshes, coastal areas and reefs were covered using solid waste arising from harbour dredging or industrial activities. Since the 1970s, land-claim mainly occurred using the industrial solid waste originating in the Tubarão Complex (Gazeta, 2016), in which the Camburi Beach (adjacent to the Tubarão Complex) is an artificial beach constructed by deposited iron mining bags. Vitória Bay is also impacted by several pollution sources such as domestic sewage, metallurgical, textile and paint industries, smelting and iron mining (Fig. 1) (Santos et al., 2017).

The Tubarão Complex $\left(20^{\circ} 17^{\prime} 03.8^{\prime \prime} \mathrm{S}\right.$ and $\left.40^{\circ} 14^{\prime} 24.9^{\prime \prime} \mathrm{W}\right)$ is located in a coastal, populated area between Vitória City and Serra (Fig. 1) housing, encompassing iron pelletizing and steel industries, plus the associated export harbours. These industries discharge many types of wastes: solid waste deposited in the Camburi Beach, liquid effluent is released directly into the sea or by an outfall, and airborne particulate material (PM) going directly from industrial processes into the atmosphere, together with matter from iron storage and open transportation to ships (Santos and Reis Jr, 2011; Santos et al., 2017).

\subsection{Abiotic and biotic sampling}

In the field, rugged dissolved oxygen ( $\mathrm{RDO} \%$ ), $\mathrm{pH}$, conductivity and temperature $\left({ }^{\circ} \mathrm{C}\right)$ of surface water were determined using a multiparameter probe (Thermo Scientific Orion Star A Series, STARA3290, USA) operated $10 \mathrm{~cm}$ below the surface. Water salinity was calculated using the conductivity and temperature data.

Surface water (SW) and sediment (SD) samples were taken simultaneously with biological samples. At the Tubarão Complex, waters were sampled approximately $100 \mathrm{~m}$ from the four points located near to the complex: Surface Water 1 (SW1) - close to the discharge of the pelletizing iron industry; Surface Water 2 (SW2) - close to the pelletizing iron industry port; Surface Water 3 (SW3) - close to the steel industry effluent discharge, and Surface Water 4 (SW4) - close to the steel industry port (Fig. 1). Sediments were sampled at the Camburi Beach, at four points located near to the complex: Sediment 1 (SD1) - adjacent to the iron pelleting industry in the infralittoral area; Sediment 2 (SD2) - adjacent to the iron pelleting industry in the overflow to the sea; Sediment 3 (SD3) - $1 \mathrm{~km}$ from the Tubarão Complex; Sediment 4 (SD4) - $5 \mathrm{~km}$ from the Tubarão Complex (Fig. 1). Atmospheric particulate matter (PM) was sampled following the method of Arrivabene et al. (2015). PM sampling in mangrove areas were not possible due to the canopy trees. Water samples were collected into pre-cleaned acid washed plastic bottles, $10-20 \mathrm{~cm}$ under water surface, acidified with ultrapure $\mathrm{HNO}_{3}$ (sub- 
boiling grade) and stored at $4{ }^{\circ} \mathrm{C}$ until analysis. Prior to analysis, water samples were filtered using a $0.45 \mu \mathrm{m}$ nitrocellulose filter. Sediment samples (approx. 10-20 cm depth intervals) were collected using a polypropylene spoon and quickly transferred into clean $1 \mathrm{~L}$ polypropylene flasks (without head-space). These were then dried at room temperature and sieved through nylon meshes $(63 \mu \mathrm{m})$.

Leaf samples of mangrove vascular trees [Rhizophora mangle (RI), Laguncularia racemosa (LA), Avicennia schaueriana (AV)], plankton (PK), shrimp Macrobranchium sp. (SH), crab Aratus sp. (CR), oyster Crassostrea rhizophorae (OS) and juvenile fish Centropomus parallelus [muscle (MU), gill (GI), kidney (KI), hepatopancreas (HP) and gonad (GO)] were collected at each site. At the Tubarão Complex, plankton, shrimp and oyster were not collected as the studied species are absent in this area. Nine specimens $(n=9)$ of each biotic sample (plants, oyster, crab, shrimp and fish) were collected together with nine plankton samples. Three pools, each consisting of three specimens or samples, were analysed in triplicate $(n=3)$. Fully expanded leaves (3rd to 5th node) of the three plant species were collected and washed with ultrapure water. Seston samples were taken along a transect between the banks of the river, collecting $20 \mathrm{~L}$ of surface water that was filtered with a plankton net of $20 \mu \mathrm{m}$; this produced a composite of phytoplankton, zooplankton and suspended particulate matter (seston). Crabs were collected by hand directly from trees roots (where they are attached) and shrimps were collected with a pitfall trap. Fish were collected with hook and line, and organs were removed and separated in the field, stored in pre-cleaned plastic recipients, and placed in liquid nitrogen to be transported to the laboratory. All biological samples were freeze-dried until constant weight, ground, and homogenized with mortar and pestle then stored at room temperature until analysis.

\subsection{Analysis of $\delta^{13} \mathrm{C}$ and $\delta^{15} \mathrm{~N}$}

Sediment samples, atmospheric particulate matter, plankton, plants, oyster, crab, shrimp and fish organs ( 1.5 to $3 \mathrm{mg}$ ) were weighed into 5 $\times 3.5 \mathrm{~mm}$ silver capsules (CEI-003-57, CE Instruments) for analysis. All the samples were pre-treated with $0.1 \mathrm{M} \mathrm{HCl}$ to remove any carbonates prior to analysis. The $\delta^{13} \mathrm{C}$ and $\delta^{15} \mathrm{~N}$ natural isotopic ratios were determined using a Flash EA 1112 Series Elemental Analyser connected via a Conflo IV to a Delta V Advantage isotope ratio mass spectrometer (IRMS) (Thermo Scientific, Bremen, Germany), in dynamic autodilution mode. The $\delta^{13} \mathrm{C}_{\mathrm{VPDB}}$ and $\delta^{15} \mathrm{~N}_{\text {Air-N2 }}$ values were used to normalize values to their respective scales, using International Atomic Energy Agency (IAEA) certified reference materials (CRMs) USGS40 and USGS41 (both L-glutamic acid). In addition, the USGS40 was used as CRM for the analytical quality control and quality assurance (AQC/QA) for both $C$ and N. For the AQC/QA, a batch of fifteen samples pairs of USGS40 and USGS41 were analysed. Long term precision for a quality control standard (dried milled topsoil) were: total C $3.79 \pm 0.13 \%$, $\delta^{13} \mathrm{C}-27.81 \pm 0.18 \%$, total $\mathrm{Nn} 0.28 \pm 0.02 \%$ and $\delta^{15} \mathrm{~N} 4.65 \pm 0.61 \%$ 。 (mean $\pm \mathrm{SD}, n=10$ ). Data processing was performed using the Isodat 3.0 software (Thermo Fisher Scientific, Bremen, Germany) and exported into Excel.

\subsection{Analysis of $\mathrm{Sr}\left({ }^{87} \mathrm{Sr} /{ }^{86} \mathrm{Sr}\right)$ and $\mathrm{Pb}$ isotopes $\left({ }^{206} \mathrm{~Pb} /{ }^{207} \mathrm{~Pb}\right.$ and $\left.{ }^{208} \mathrm{~Pb} /{ }^{207} \mathrm{~Pb}\right)$}

Sediment and particulate matter samples ( $0.1 \mathrm{~g}$ dry weight each) were digested with $4 \mathrm{~mL}$ of nitric acid and $1 \mathrm{~mL}$ of hydrochloric acid (ultrapure, sub-boiling grade). Biotic samples ( $0.1 \mathrm{~g}$ dry weight each) were digested with $4 \mathrm{~mL}$ of nitric acid, $1 \mathrm{~mL}$ of hydrochloric acid (ultrapure, sub-boiling grade) and $0.5 \mathrm{~mL}$ of hydrogen peroxide (ultrapure) in pre-cleaned PTFE close-vessels, using a Microwave Accelerated Reaction System (MARS Xpress TM; CEM Corporation, USA) (Souza et al., 2013). Prior to measurement, all digested samples were filtered using $0.45 \mu \mathrm{m}$ nitrocellulose filter to remove remaining particles according to the method described in USEPA 200.8 (2009). All glassware and polypropylene bottles/containers used in the digestion procedure were leached with a sulphuric/nitric acid solution overnight and further rinsed with ultrapure water.

All reagents used for the ion exchange columns and isotope analyses were trace grade. Glassware was cleaned with $10 \%$ Decon $90^{\mathrm{TM}}$, followed by $10 \%$ nitric acid soak. An aliquot of each digest was purified for $\mathrm{Sr}$ isotope analysis by using a cation exchange resin (Bio Rad AG $50 \mathrm{~W}$ $\times$ 8200-400 mesh hydrogen form) to isolate Sr from other elements. Most purified samples were dried down and loaded directly onto a

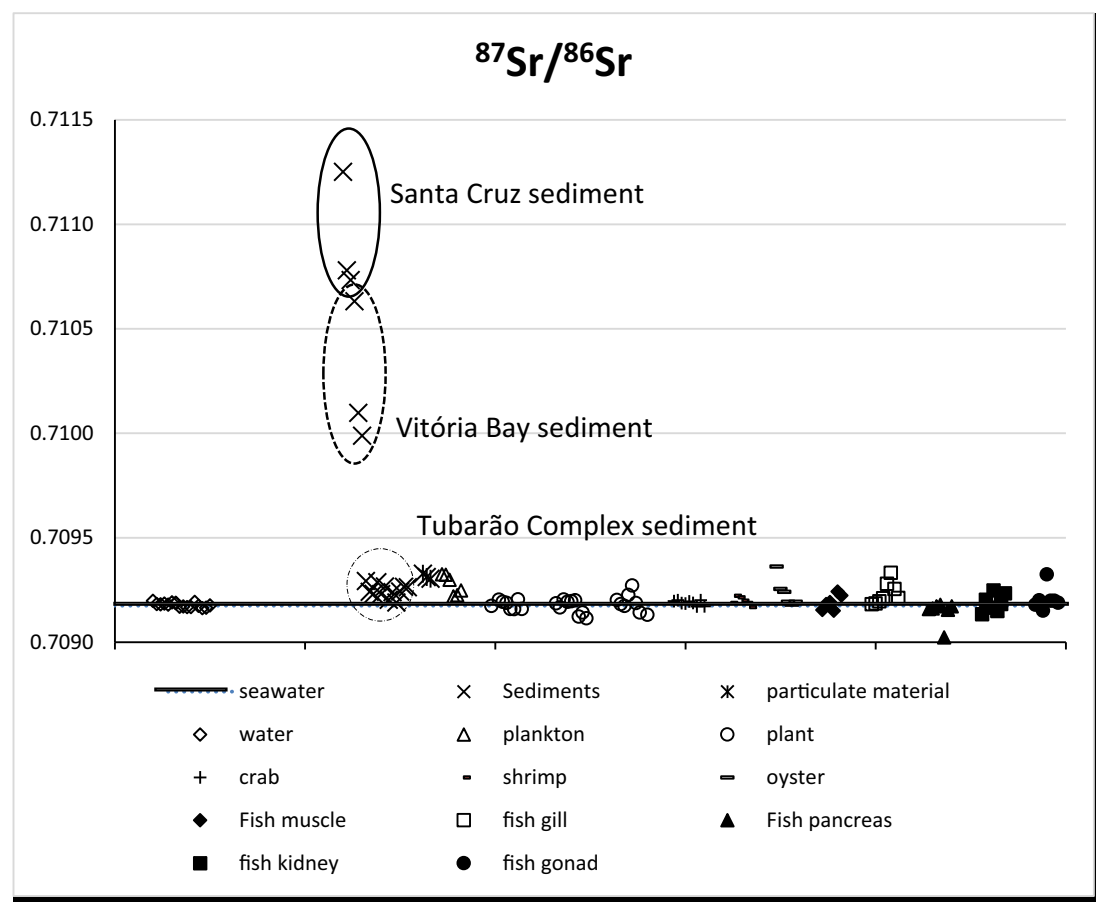

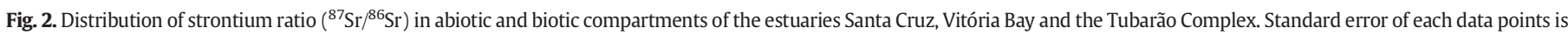
approximately the size of the data point symbol. Circles differentiate the strontium signature of the sediments of both estuaries. There was no difference between the other matrices. 
tantalum filament. Samples known to have a low Sr concentration were loaded on a rhenium filament with a tantalum activator solution. The ${ }^{87} \mathrm{Sr} /{ }^{86} \mathrm{Sr}$ ratio was determined using a VG Sector 54 , Thermal Ionisation Mass Spectrometer (TIMS), running either a 1 or $2 \mathrm{~V}$ three-cycle dynamic procedure. The mass fractionation was exponentially corrected using the naturally invariant ${ }^{86} \mathrm{Sr} /{ }^{88} \mathrm{Sr}$ ratio of 0.1194 . A maximum of 150 ratios were collected. At least one certified reference material SRM987 (NIST, USA) was run in each batch of analysis for quality control, producing a mean value for this study of ${ }^{87} \mathrm{Sr} /{ }^{86} \mathrm{Sr}=0.710249 \pm$ 0.000021 (2SD), $n=18$. (Certificate ${ }^{87} \mathrm{Sr} /{ }^{86} \mathrm{Sr}=0.71034 \pm 0.00026$ ). A typical column and instrumental procedure blank for this period was $177 \mathrm{pg} \mathrm{Sr}$.

Lead was purified from the matrix by passing an aliquot of the digested sample through an anion exchange resin (Bio Rad AG1-X8 200-400 mesh in chloride form). The purified samples were dried down and loaded onto a rhenium filament with a silica gel emitter solution. The ${ }^{206} \mathrm{~Pb} /{ }^{207} \mathrm{~Pb}$ and ${ }^{208} \mathrm{~Pb} /{ }^{207} \mathrm{~Pb}$ ratios were determined by using a static procedure on the TIMS instrument. The voltage of the signal was very dependent on the sample, ranging from $5 \mathrm{~V}$ to $0.005 \mathrm{~V}$. A maximum of 250 ratios were collected. No mass bias correction was applied for these samples. At least one certified reference material CRM981 (NIST, USA) was run in each batch of analysis for quality control, producing a mean value for this study of ${ }^{206} \mathrm{~Pb} /{ }^{207} \mathrm{~Pb} 1.0947 \pm 0.0005$ (2SD), ${ }^{208} \mathrm{~Pb} /{ }^{207} \mathrm{~Pb} 2.3661 \pm 0.0013(2 \mathrm{SD}) n=29$. (CRM981 $={ }^{206} \mathrm{~Pb} /{ }^{207} \mathrm{~Pb}$ $\left.1.09333 \pm 0.00033(2 \mathrm{SD}),{ }^{208} \mathrm{~Pb} /{ }^{207} \mathrm{~Pb} 2.37044\right)$.

\subsection{Statistical analysis}

Data are reported as mean \pm standard deviation (after testing for normal distributions). One-way analysis of variance (ANOVA), followed by the Tukey's test or a $t$-test (when there was two matrices for comparison) was applied with a significance level $P<0.05$. Discriminant analysis was carried out on the entire data matrix (without normalization), using the stepwise mode, considering previous reports (Wunderlin et al., 2001).
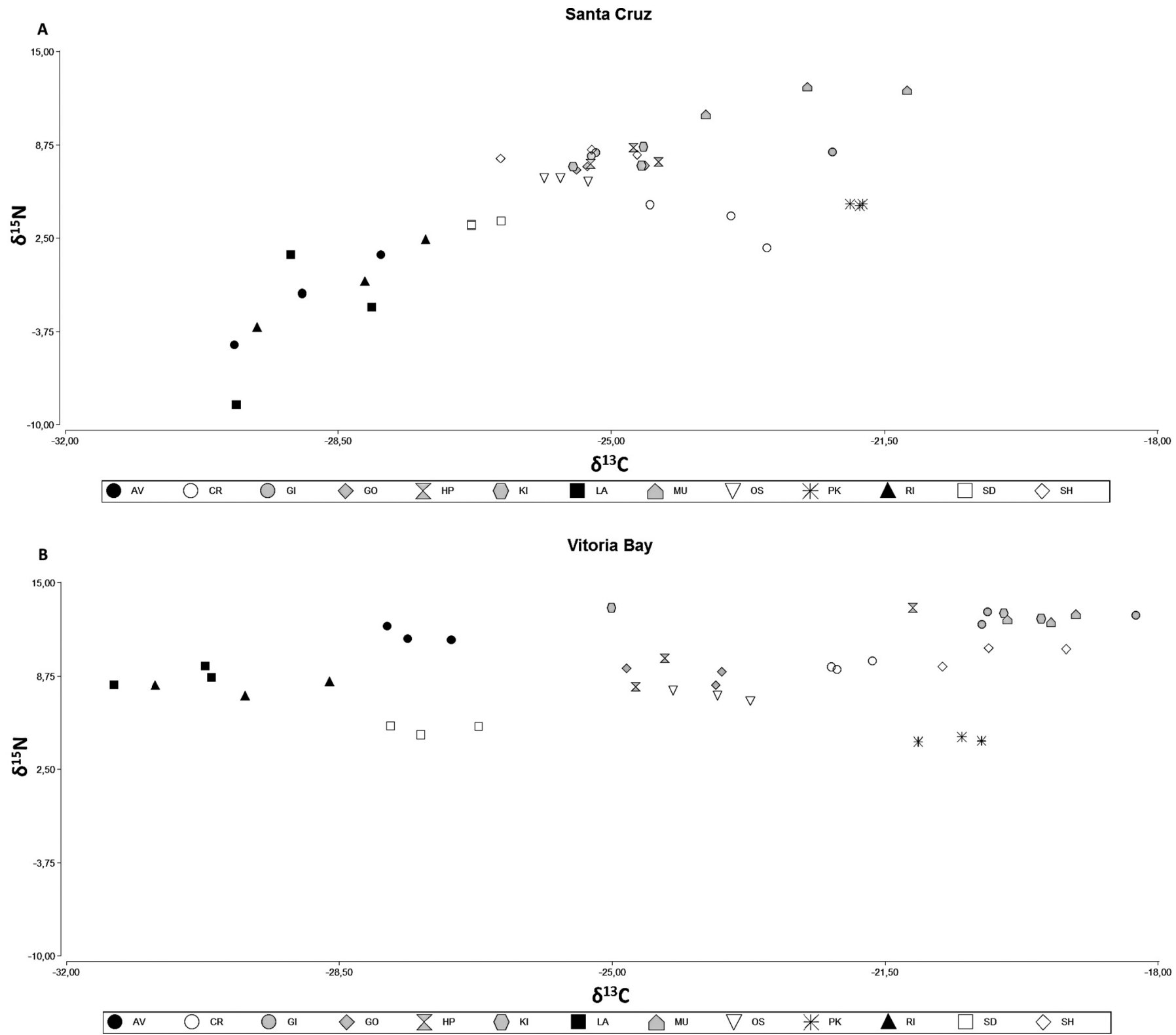

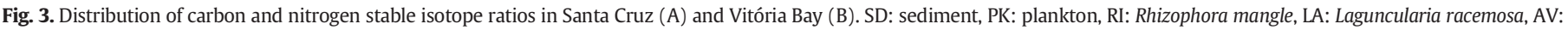

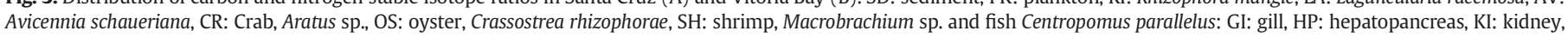
MU: muscle, GO: gonad. 


\section{Results and discussion}

\subsection{Strontium fingerprint}

The global general ${ }^{87} \mathrm{Sr} /{ }^{86} \mathrm{Sr}$ ratio of continental river water tends to be relatively high (approx. 0.711 ) although it can vary reflecting the ${ }^{87} \mathrm{Sr} /{ }^{86} \mathrm{Sr}$ of the underlying geology (Capo et al., 1998). The global marine ${ }^{87} \mathrm{Sr} /{ }^{86} \mathrm{Sr}$ value (0.709180; McArthur et al., 2001) is significantly more homogeneous as it has a mixing time in the order of thousands of years. Water samples from all sites present results more consistent with the marine global value (Table 1S and Fig. 2), although the conductivity/salinity differs among sites; Santa Cruz presents higher salinity, followed by Vitória Bay and the lowest salinity is in the Tubarão Complex (Table 4S). The conductivity/salinity differences may be explained by each site characteristics. As described before, the Tubarão Complex is a coastal area, with a minor influence of river water. The major influence of freshwater comes from effluent discharged directly in the coastal area and from submarine water emissions from the industries in the Tubarão Complex. Vitória Bay is an estuarine area influenced by five rivers which receive marine water from the Espirito Santo Bay; it is a semi-enclosed bay with little influence from the open sea. The Santa Cruz estuary is influenced by only two rivers which originate from groundwater and is an open estuary with a strong influence of marine water. The high salinity date in Espírito Santo, especially in Santa Cruz calculated in this study correspond to data measured by Aquarius satellite, on 2013, for this Brazilian region (NASA, 2014).

The sediment ${ }^{87} \mathrm{Sr} /{ }^{86} \mathrm{Sr}$ ratios of the three sites vary markedly, with Santa Cruz the highest ratio and the Tubarão Complex the lowest

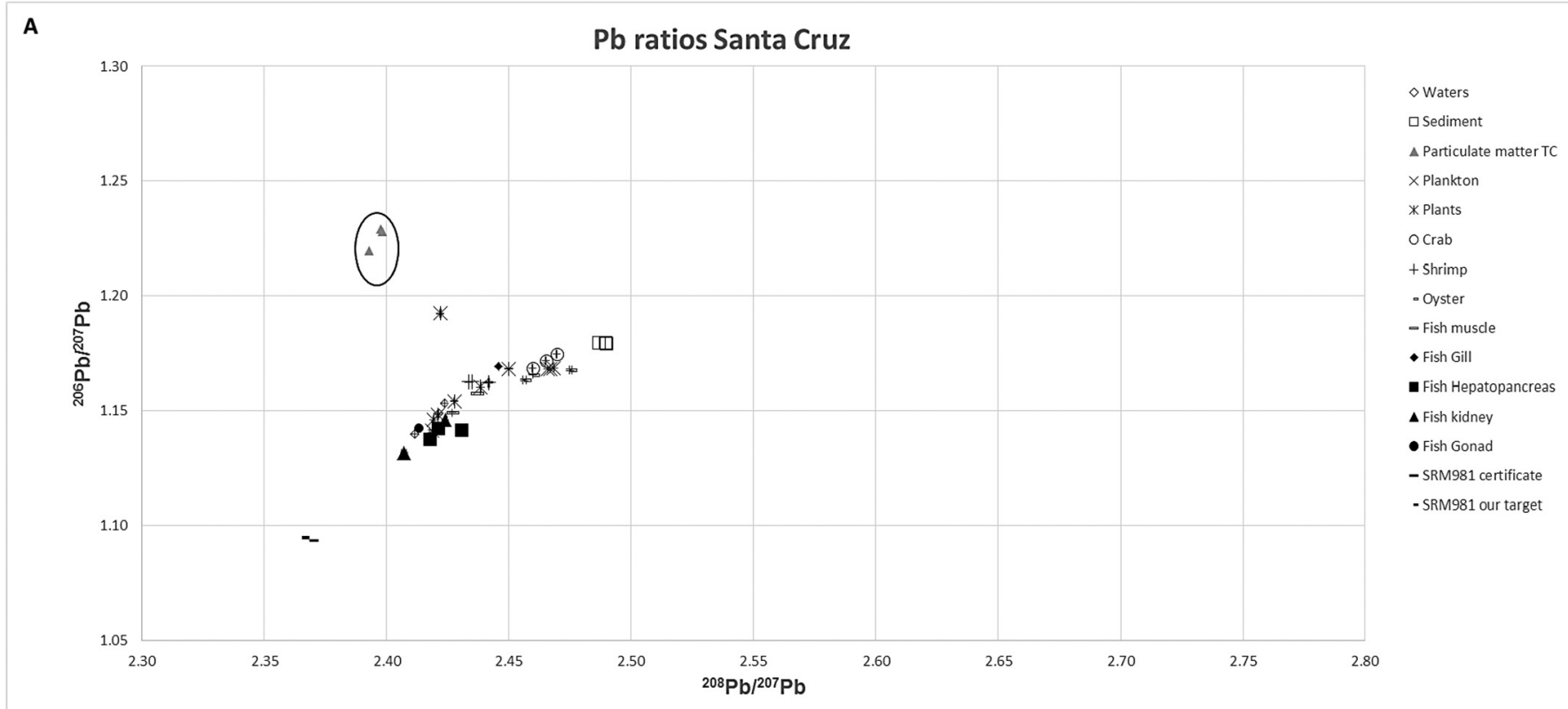

B

$\mathrm{Pb}$ ratios Vitoria Bay

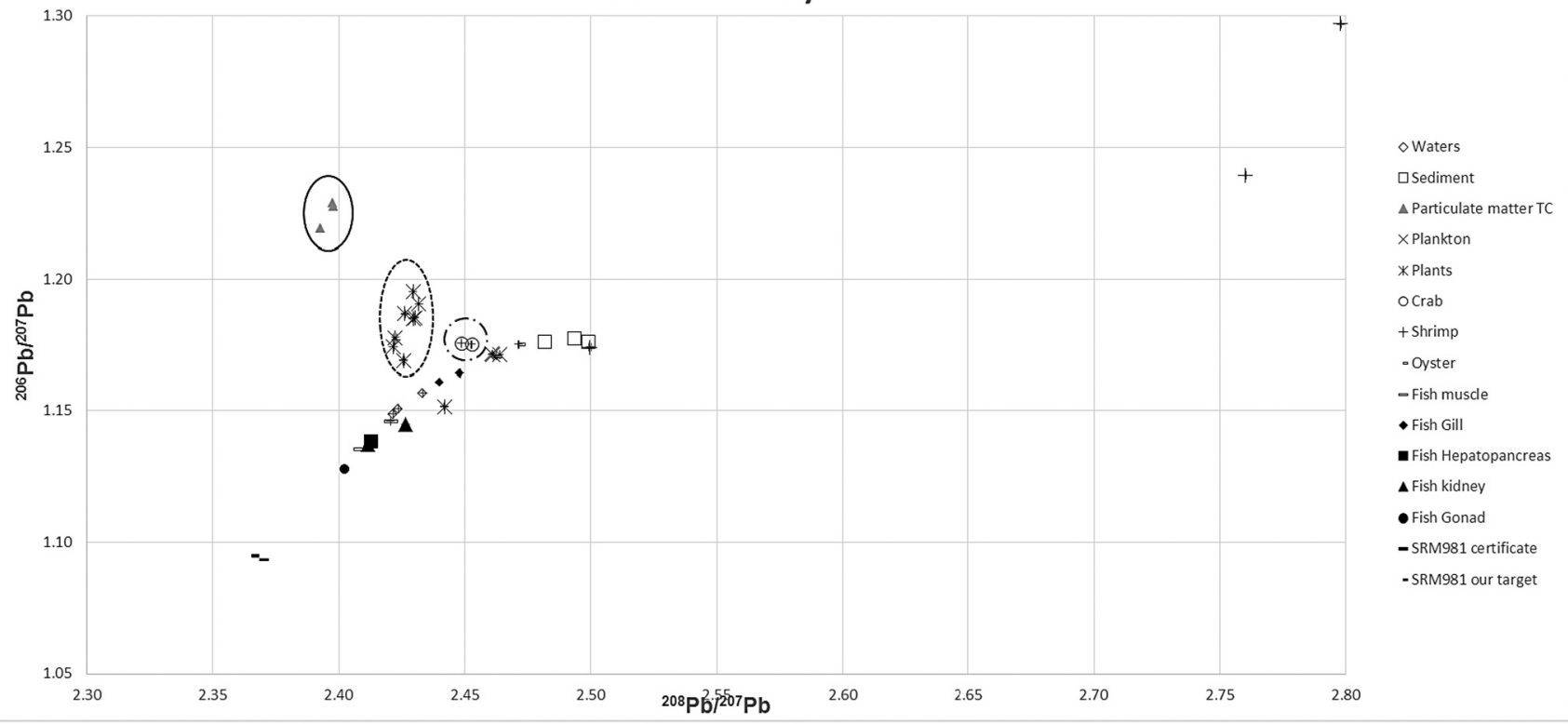

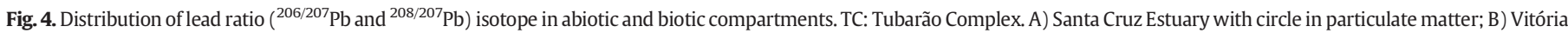

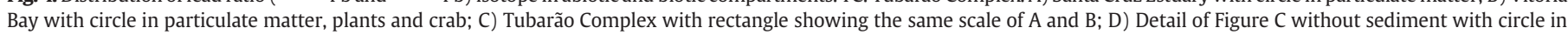
particulate matter, plants and crab. 

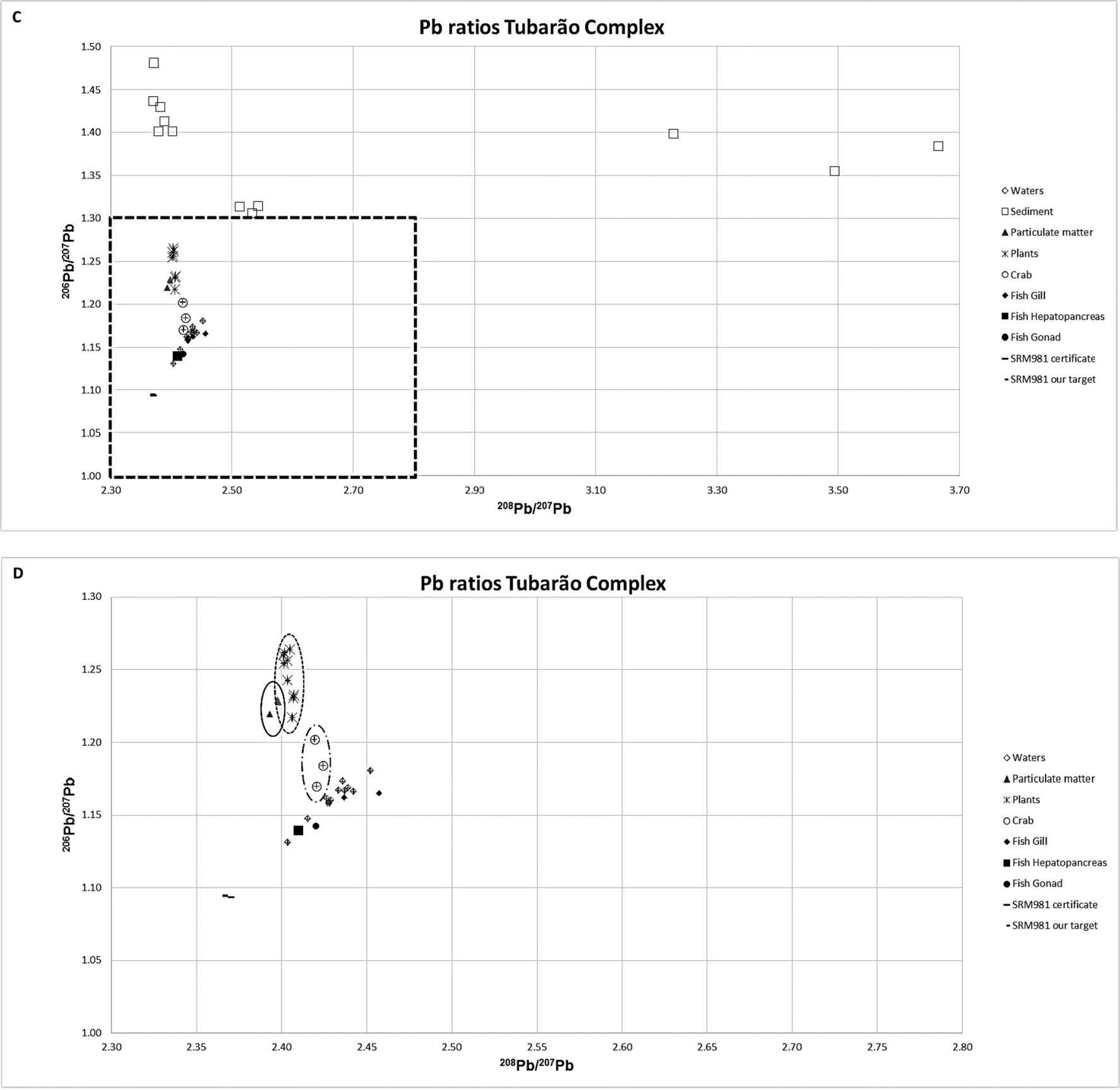

Fig. 4 (continued)

(Fig. 2). This indicates that the sediment origins contain different mixes of the expected high continental ${ }^{87} \mathrm{Sr} /{ }^{86} \mathrm{Sr}$ and the lower ${ }^{87} \mathrm{Sr} /{ }^{86} \mathrm{Sr}$ of marine organism detritus, with Santa Cruz mostly influenced by continental ${ }^{87} \mathrm{Sr} /{ }^{86} \mathrm{Sr}$. Vitória Bay presented intermediate values in agreement with a mixed influence of both continent and marine values. Conversely, the sediment from the Tubarão Complex shows values consistent with marine detritus (Fig. 2). Differences in the sediment ${ }^{87} \mathrm{Sr} /{ }^{86} \mathrm{Sr}$ indicate that sediments are more influenced than water by particulate matter arising from the continent, transported by rivers and settling in the estuarine area close to the continent (Santa Cruz and, in a less proportion, Vitória Bay), while sediments from the Tubarão Complex are dominated by marine detritus because of its location close to the sea (Fig. 1).
Previous studies of river sediments from the Espírito Santo state reported ${ }^{87} \mathrm{Sr} /{ }^{86} \mathrm{Sr}$ ratios ranging from 0.737 to 0.753 (ICMBio, 2018), showing that the continental values are higher than those found in this work. Although the ${ }^{87} \mathrm{Sr} /{ }^{86} \mathrm{Sr}$ ratio can also be affected by the quantity of biological material in the sediment, it is clear the influence of seawater ${ }^{87} \mathrm{Sr} /{ }^{86} \mathrm{Sr}$ in biotic samples. It is of note that the current sampling occurred 8 months before the Mariana disaster (ICMBio, 2018), an iron mining accident which changed the ${ }^{87} \mathrm{Sr} /{ }^{86} \mathrm{Sr}$ of marine areas in the coast of Espírito Santo.

Biotic sample ${ }^{87} \mathrm{Sr} /{ }^{86} \mathrm{Sr}$ data from all the sites suggest that the $\mathrm{Sr}$ value of the biota is mainly influenced by marine water (Fig. 2). The influence of marine water on mangrove plants is also emphasized by Lin and Sternberg (1994) based on the analysis of oxygen isotopes in 
Rhizophora mangle, which showed that mangrove plants use surfacesoil and seawater rather than groundwater as water source, even when the water has a high salinity. The results here suggest that the ${ }^{87} \mathrm{Sr} /{ }^{86} \mathrm{Sr}$ of all analysed biota (plants and animals) is consistent with marine water, which can result from acclimatisation of this biota to an environment dominated by saline water rather than riverine freshwater. Moreover, it is concluded that sediment does not have a detectable influence on the ${ }^{87} \mathrm{Sr} /{ }^{86} \mathrm{Sr}$ of estuarine biota.

\subsection{Trophic relationships}

The $\delta 13 \mathrm{C}$ values for mangrove trees ranged from $-27.5 \%$ o to $-30.6 \%$ for all studied sites which is typical for terrestrial plants fixing $\mathrm{C}$ using a C3 photosynthetic pathway. The PK had $813 \mathrm{C}$ value of approximately $-21 \%$ o (Table $1 \mathrm{~S}$ and Fig. 3 ) which agrees with previously reported values for estuarine phytoplankton (Bouillon et al., 2011). As our samples included a mixture of both phytoplankton and zooplankton (seston), we anticipate that the value is slightly more $13 \mathrm{C}$ enriched than that of C3 phytoplankton alone. Although phytoplankton can be separated from zooplankton to evaluate individual $\delta 13 \mathrm{C}$ values, this was beyond the scope of this study. However, our isotope analysis did not indicate any contamination with organic pollutants, such as fossil fuels which are typically $13 \mathrm{C}$ depleted and readily detectable using stable isotopes.

The $\delta^{15} \mathrm{~N}$ values of Santa Cruz show an increasing trend from mangrove trees to fish muscle, ranging from -3.1 to 12.0 (Table $1 \mathrm{~S}$, Fig. 3A). This trend is expected in an ecosystem containing plants, phytoplankton, and zooplankton to higher animals (fish in this case) (Griboff et al., 2018; Monferrán et al., 2016). Therefore, the $\delta^{15} \mathrm{~N}$ values for the food web present in Santa Cruz estuary agree with those expected for a natural, less impacted, aquatic environment. Conversely, $\delta{ }^{15} \mathrm{~N}$ values observed in Vitória Bay, ranging from 4.5 to 12.7 (Table 1S, Fig. 3B), show an almost linear behaviour across trophic levels. As expected in a food web, $\delta^{15} \mathrm{~N}$ values were higher in fish tissues (GI, HP, KI, MU and GO) from Vitória Bay, but CR, OS and SH also showed significantly higher values in Vitória Bay with respect to Santa Cruz (Table 1S, Fig. 3). Moreover, mangrove trees (RI, LA and AV) also had significant higher values for $\delta^{15} \mathrm{~N}$ (Table 1S, Fig. 3). The change in the slope corresponding to $\delta^{15} \mathrm{~N}$ from Santa Cruz to Vitória Bay (Fig. 3A vs $3 \mathrm{~B}$ ), in addition to higher $\delta^{15} \mathrm{~N}$ values observed in mangrove trees, macroinvertebrates and fish inhabiting Vitória Bay with respect to Santa Cruz (Table 1S), showed the presence of different nitrogen sources between both estuaries.

Significant differences in $\delta{ }^{15} \mathrm{~N}$ among different species were observed $(P<0.05)$ when comparing both estuaries (Table $1 \mathrm{~S}$ and Fig. 2B). The $\delta^{15} \mathrm{~N}$ made it possible to separate, at least, three trophic levels within the food web in both ecosystems. The lowest $\delta^{15} \mathrm{~N}$ values were found in the PK (4.7\% in Santa Cruz and 4.5\% in Vitória Bay; Table 1S and Fig. 2B), the next level was represented by the primary consumer, the SH (Macrobranchium sp.) showing $\delta^{15} \mathrm{~N}$ of $8.5 \%$ and $10.2 \%$ in Santa Cruz and Vitória Bay, respectively (Table 1S and Fig. 2B). As expected, fish muscle showed the highest $\delta^{15} \mathrm{~N}$ values in both estuaries with $12 \%$ and $12.6 \%$ for Santa Cruz and Vitória Bay, respectively (Table $1 \mathrm{~S}$ and Fig. $2 \mathrm{~B}$ ). Hence the range of $\delta^{15} \mathrm{~N}$ values among the studied species suggests an increasing trophic cascade: plankton-shrimp-fish, consistent with the $3-5 \%$ increasing in $\delta^{15} \mathrm{~N}$, commonly proposed per trophic level (Hobson et al., 2002).

The difference of $\delta^{15} \mathrm{~N}$ between the plants (medium value among the tree species RM, LA and AV) and CR (primary consumer) was 3.5\% in Santa Cruz and 9.4\% in Vitória Bay, which suggests that the sampled plants consumed by the Vitória Bay crabs may be mixed with sediment that has a higher $\delta^{15} \mathrm{~N}$ value as this crab species is a restrictive leaffeeder (Miranda et al., 2017; Rabelo et al., 2009; Yeager et al., 2016). The isotope differences between the crab and fish were $8.5 \%$ in Santa Cruz and 3.6\% in Vitória Bay suggesting that in this site the crabs were potentially the key food source for the fish, whereas in Santa Cruz this was not the case, and the shrimp was the main food source as has previously been reported for this species (Cerqueira and Tsuzuki, 2009). The difference between the two sites may be the result of differences in anthropogenic pressures, in particular fishing in Vitória Bay. Our isotope analysis also characterized another trophic chain for this estuarine foodweb: plants-crab-fish.

It is also possible to assume a third trophic chain between plankton and suspension-feeding oysters in which the difference between $\delta^{15} \mathrm{~N}$ values were $1.7 \%$ and $2.9 \%$ in Santa Cruz and Vitória Bay, respectively (Table 1S and Fig. 2B). The slightly difference between the two sites may have arisen because the Santa Cruz site there is greater influence from the marine water into the estuary which in turn reduces the suspended sediment load, directly affecting the food source of the oysters.

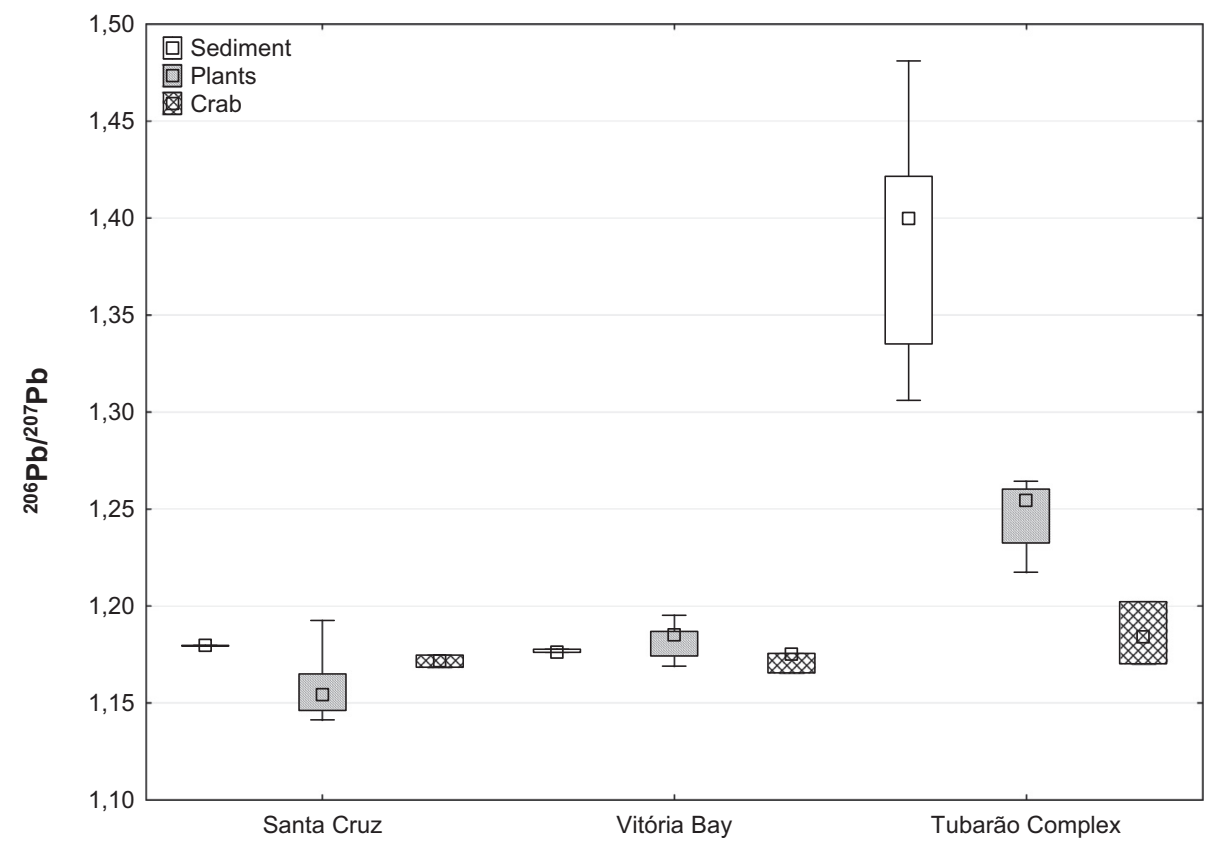

Fig. 5. Blox Plot showing ${ }^{206} \mathrm{~Pb} /{ }^{207} \mathrm{~Pb}$ of sediment, plants and crab from Santa Cruz, Vitória Bay and Tubarão Complex. Median; Box: 25\%-75\%; Whisker: Non-Outlier Range. 
These results confirm the anthropogenic influence in the Vitória Bay area (higher $\delta^{15} \mathrm{~N}$ values), probably associated with sewage, urban runoff and other human activities in this area (Fenech et al., 2012). Further research is necessary to establish how the human influence is differentially affecting diverse strata of the food web, namely, phytoplankton, zooplankton, crabs, oyster, shrimp and fish. It is evident from the results here that the lower components of the web (plankton and plants) are more affected than the higher organisms (crabs, oysters, shrimps and fish) (Fig. 3A vs 3B). Different responses of various food-web organisms, in response to bioaccumulation of metal/metalloids has been reported (Monferrán et al., 2016). Therefore, establishing that higher $\delta^{15} \mathrm{~N}$ values in an aquatic ecosystem could be associated with anthropogenic negative impacts (sewage and other activities) allows the future use of this parameter to distinguish between clean and polluted aquatic environments. Further research is necessary to confirm this hypothesis, but our current results provide a reference point for future comparisons.

\subsection{Lead fingerprint}

The analysis of ${ }^{206} \mathrm{~Pb} /{ }^{207} \mathrm{~Pb}$ and ${ }^{208} \mathrm{~Pb} /{ }^{207} \mathrm{~Pb}$ ratios (Table $1 \mathrm{~S}$ and Fig. 4) confirmed that the $\mathrm{Pb}$ isotope value in all sampling sites was similar to typical metallurgical activities, as described by Bollhöfer and Rosman (2000) and Komárek et al. (2008). As no leaded petrol has been used in Brazil since the 1980s (Bollhöfer and Rosman, 2000), it is suggested that the Brazilian anthropogenic aerosols containing $\mathrm{Pb}$ come from industrial sources, which include mining, smelting, coal burning, crushing, grinding, separation, refining and tailings management. All of these processes produce large quantities of dust (coarse particulates) and aerosols, including the road and rail transport of ore (Reed and Westman, 2005). Although most mining operations produce dusts, high temperature processes produce fumes and fine particulates, potentially laden with metals and metalloids that are present in the ore (Bollhöfer and Rosman, 2000).

It is of note that one out of three studies sites (the Tubarão Complex) had the highest sediment $\mathrm{Pb}$ isotopic ratios $\left({ }^{206} \mathrm{~Pb} /{ }^{207} \mathrm{~Pb}\right.$ and ${ }^{208} \mathrm{~Pb} /{ }^{207} \mathrm{~Pb}$ ) (Table $1 \mathrm{~S}$ and Fig. 4). Furthermore, the lead isotopic value observed in this area is characteristic of anthropogenic sources. This can be explained by the presence of solid waste from metallurgical activities at this site, as shown by the highest values observed in the sediment sampled close to the complex (Fig. 4C); there are also some high values for ${ }^{206} \mathrm{~Pb} /{ }^{207} \mathrm{~Pb}$ in mangrove plants and crabs from this area (Fig. 4D). Conversely, there was no significant $\mathrm{Pb}$ isotopic variation between the surface water of Santa Cruz and Vitória Bay with respect to the Tubarão Complex (Table 1S and Fig. 4). This result can be explained in terms of the low solubility of lead in water (Angel et al., 2015).

On the other hand, when comparing PM from with Tubarão Complex with abiotic and biotic samples from Vitória Bay, we observed similar Pb isotopic ratios for both areas (Fig. 4B and D, denoted by circles), which suggests that Vitória Bay is being affected with PM arising from the metallurgical complex. It is also of note that mangrove plants are mainly affected by PM deposition at these both areas (Fig. 4B and D, denoted by circles). Moreover, crabs sampled from mangrove plants in the Tubarão Complex show a lead isotopic value similar to that observed with PM and plants from this area (Fig. 4D). Further comparison of the reference area (Santa Cruz) biotic and abiotic samples with those PM sampled at Tubarão Complex indicate that plants and crabs from Santa Cruz did not show the same lead isotopic value when compared with Vitória Bay or Tubarão Complex, which is explained by the position of Santa Cruz north from Vitória Bay, being dependent on the wind variations in this area.

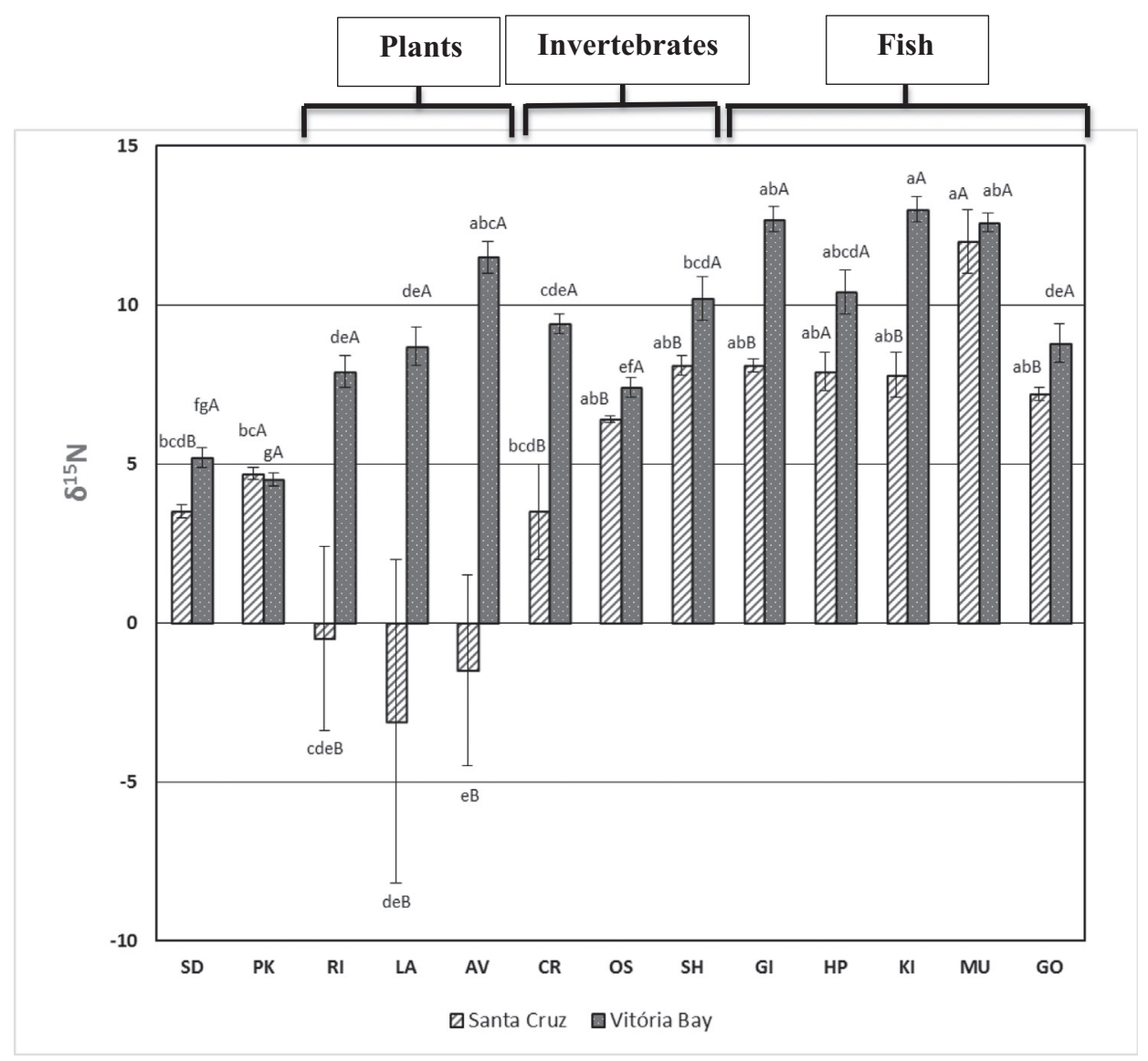

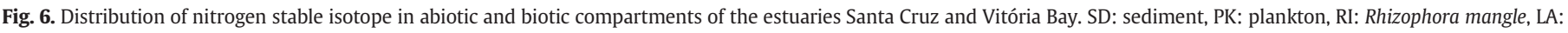

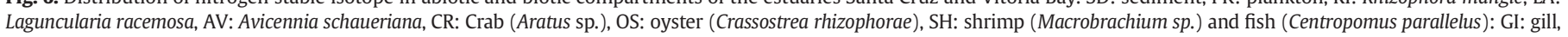
HP: hepatopancreas, KI: kidney, MU: muscle, GO: gonad. 
The meteorological variables more related with atmospheric particulate matter spread were wind velocity and precipitation (Santos et al., 2016). Mattiuzzi and Marchioro (2012) described the wind prevalence in Vitória as Northeast (NE) with a velocity varying from 2.1-3.6 m/s; however, when there is a Cold Front (CF) or South Atlantic Convergence Zone (SACZ) events in the region of Vitória city, the direction and velocity of the winds changes increasing the velocity to $3.6-5.7 \mathrm{~m} / \mathrm{s}$ and the predominant direction is to the Southeast. This phenomenon could affect the atmospheric contamination. During summer, which is the rainy season (Incaper, 2018), the atmospheric particulate matter can be influenced by pluviosity (heavy rainfall) (Santos et al., 2016) and the particulate material could precipitate and so not travelling longer distances. However, during the CF and SACZ occurrence, mainly in autumn/winter/spring, the rainfall is lower (Incaper, 2018) and the wind velocity is higher probably carrying the atmospheric particulate matter far from the Tubarão Complex at northeast direction affecting areas such as Santa Cruz. Our current results confirm those of Santos et al. (2017), who show the metallurgical activity of the Tubarão Complex to be the main pollution source of the particulate matter in Vitória Bay, and in second instance Santa Cruz.

\subsection{Integrative stable isotope analysis}

Although the analysis of individual studied parameters is valuable, as many factors are involved in producing the flux relationships then multivariate statistical methods are required to interrogate those results. Multivariate statistics helps to confirm trends, differences, etc., by reducing or summarising the number of variables necessary to evaluate a given scenario (Wunderlin et al., 2001). In this case, multivariate methods were required to verify the differences between three studied areas, and identify those parameters presenting the strongest influence on the patterns (through data reduction). Therefore, we carried out a discriminant analysis (DA) using the entire dataset, with the sampling location as the grouping variable and all studied parameters included in a combined matrix (sediment, mangrove plants, invertebrates, fish, etc.). The DA shows that three out of five measured isotopic ratios $\left({ }^{206} \mathrm{~Pb} /{ }^{207} \mathrm{~Pb} ; \delta^{15} \mathrm{~N}\right.$ and $\left.{ }^{87} \mathrm{Sr} /{ }^{86} \mathrm{Sr}\right)$ were sufficient to indicate the differences between three studied areas (Tables $2 \mathrm{~S}$ and $3 \mathrm{~S}$ ).

Box plots from ${ }^{206} \mathrm{~Pb} /{ }^{207} \mathrm{~Pb}$, corresponding to isotopic values found in sediment, mangrove plants and crabs collected at three studied areas (Fig. 5) and the entire dataset (Fig. 4) show that the lead isotopic value is sufficient to differentiate Santa Cruz and Vitória Bay from the Tubarão Complex.

On the other hand, Fig. 6 shows comparative $\delta^{15} \mathrm{~N}$ values between Santa Cruz and Vitória Bay and, with Fig. 2, shows clear differences in the nitrogen isotopic value between a reference area (Santa Cruz) and the impacted area (Vitória Bay). In addition, Fig. 6 clearly shows that mangrove plants presented a greater difference compared to other studied components ( sediment, crustaceans, fish, etc.), again suggesting that $\delta^{15} \mathrm{~N}$ can help to differentiate clean from polluted areas.

Finally, the multivariate methods have given an independent, objective mathematical-statistical approach which supports the trends observed using traditional methods (plots, tables, etc.). Moreover, discriminant analysis reduced the number of stable isotopes necessary to afford a good differentiation without the loss of important information.

\section{Conclusions}

The measurement of stable isotopes shows that the Sr isotope ratios are strongly influenced by the marine water, and this influence is translated through the food web. It is of note that the sediment is the only compartment affected by the continental Sr signature although this influence was not translated to the studied biota.

Lead isotopic measurements of sediments from the Tubarão complex show clear differences with other studied areas, but there is no strong influence on other environmental compartments. In addition, the $\mathrm{Pb}$ isotopic content corresponding to PM showed similar values throughout three studied areas, while plants and crabs inhabiting Vitória Bay, close to the Tubarão complex, seem to be more influenced for atmospheric particulate matter. Further studies are necessary to fully interrogate this pattern.

Nitrogen isotopic measurements demonstrate that Vitória Bay is under high anthropogenic pressures, resulting in higher $\delta^{15} \mathrm{~N}$, which is likely to be associated with human sewage from the neighbour city, nutrients and fertilisers from the catchment, and other human activities (industry, etc.). Mangroves were greatly impacted by higher levels of $\delta{ }^{15} \mathrm{~N}$, suggesting that these plants could be used to distinguish between clean and polluted estuaries.

Finally, it is emphasized here that the combination of techniques and components used in the present study constitute a comprehensive toolkit for the evaluation of estuarine mangrove systems affected by anthropogenic contaminants. This tool-kit includes knowledge of the sources, fate and sinks of contaminants, and integrates the ecological characteristics and contamination sources. An overall goal should be to create a reliable tool-kit that can be used worldwide for the study of pollution in estuaries and other areas affected by similar pollution sources.

\section{Acknowledgements}

This study was supported by FAPESP (São Paulo Research Foundation, Grant 2014/05701-0) Sao Paulo, Brazil, CONICET (Argentinean National Research Council, FONCyT/PICT-1597 and FONCyT/PICT-1411) and Science and Technology Office from Córdoba National University, Argentina. The James Hutton Institute received funding from the Rural and Environmental Science and Analytical Services Division (RESAS) of the Scottish Government. Dr. I.C. Souza acknowledges FAPESP (Grant 2014/04832-3 and 2015/05258-1). Authors kindly acknowledges to India Weidle for her technical assistance.

\section{Appendix A. Supplementary data}

Supplementary data to this article can be found online at https://doi. org/10.1016/j.scitotenv.2018.05.302.

\section{References}

Angel, B.M., Apte, S.C., Batley, G.E., Raven, M.D., 2015. Lead solubility in seawater: an experimental study. Environ. Chem. 13 (3), 489-495.

Arrivabene, H.P., Souza, I.C., Có, W.L.O., Conti, M.M., Wunderlin, D.A., Milanez, C.R.D., 2015. Effect of pollution by particulate iron on the morphoanatomy, histochemistry, and bioaccumulation of three mangrove plant species in Brazil. Chemosphere 127, 27-34

Baroni, M.V., Podio, N.S., Badini, R.G., Inga, M., Ostera, H.A., Cagnoni, M., Gautier, E.A. García, P.P., Hoogewerff, J., Wunderlin, D.A., 2015. Linking soil, water, and honey composition to assess the geographical origin of Argentinean honey by multielemental and isotopic analyses. J. Agric. Food Chem. 63 (18), 4638-4645.

Bayen, S., 2012. Occurrence, bioavailability and toxic effects of trace metals and organic contaminants in mangrove ecosystems: a review. Environ. Int. 48, 84-101.

Bollhöfer, A., Rosman, K.J.R., 2000. Isotopic source signatures for atmospheric lead: the southern hemisphere. Geochim. Cosmochim. Acta 64 (19), 3251-3262.

Bond, A.L., 2010. Relationships between stable isotopes and metal contaminants in feathers are spurious and biologically uninformative. Environ. Pollut. 158 (5), 1182-1184.

Bouillon, S., Connolly, R.M., Gillikin, D.P., 2011. Use of stable isotopes to understand food webs and ecosystem functioning in estuaries. In: Wolanski, E., DS, McLusky (Eds.) Treatise on Estuarine and Coastal Science. 7, pp. 143-173.

Capo, R.C., Stewart, B.W., Chadwick, O.A., 1998. Strontium isotopes as tracers of ecosystem processes: theory and methods. Geoderma 82 (1), 197-225.

Cerqueira, V.R., Tsuzuki, M.Y., 2009. A review of spawning induction, larviculture, and juvenile rearing of the fat snook, Centropomus parallelus. Fish Physiol. Biochem. 35 (1), 17-28.

Cheng, H., Hu, Y., 2010. Lead (Pb) isotopic fingerprinting and its applications in lead pollution studies in China: a review. Environ. Pollut. 158 (5), 1134-1146.

Chow, T.J., Earl, J.L., 1970. Lead aerosols in the atmosphere: increasing concentrations. Science 169 (3945), 577-580.

Chow, T.J., Earl, J.L., 1972. Lead isotopes in North American coals. Science 176 (4034), 510-511.

Chow, T.J., Johnstone, M.S., 1965. Lead isotopes in gasoline and aerosols of Los Angeles basin, California. Science 147 (3657), 50-503. 
Chow, T.J., Bruland, K.W., Bertine, K., Soutar, A., Koide, M., Goldberg, E.D., 1973. Lead pollution: records in Southern California coastal sediments. Science 181 (4099), $551-552$.

Chow, T.J., Snyder, C.B., Earl, J.L., 1975. Isotope Ratios of Lead as Pollutant Source Indicators. Univ. of California, San Diego, La Jolla.

Elliott, M., Whitfield, A.K., 2011. Challenging paradigms in estuarine ecology and management. Estuar. Coast. Shelf Sci. 94 (4), 306-314.

Fenech, C., Rock, L., Nolan, K., Tobin, J., Morrissey, A., 2012. The potential for a suite of isotope and chemical markers to differentiate sources of nitrate contamination: a review. Water Res. 46 (7), 2023-2041.

Gazeta, 2016. http://especiais.gazetaonline.com.br/aterro/ [Access: 08/02/2017].

Griboff, J., Horacek, M., Wunderlin, D.A., Monferrán, M.V., 2018. Bioaccumulation and trophic transfer of metals, As and Se through a freshwater food web affected by antrophic pollution in Córdoba, Argentina. Ecotoxicol. Environ. Saf. 148, 275-284.

Hobson, K.A., Fisk, A., Karnovsky, N., Holst, M., Gagnon, J.M., Fortier, M., 2002. A stable isotope $(\delta 13 \mathrm{C}, \delta 15 \mathrm{~N})$ model for the north water food web: implications for evaluating trophodynamics and the flow of energy and contaminants. Deep-Sea Res. II 49, 5131-5150.

Hogarth, P., 1999. The Biology of Mangroves. Ed. Oxford University Press (228p).

Ikemoto, T., Tu, N.P.C., Okuda, N., Iwata, A., Omori, K., Tanabe, S., Tuyen, B.C., Takeuchi, I., 2008. Biomagnification of trace elements in the aquatic food web in the Mekong Delta, South Vietnam using stable carbon and nitrogen isotope analysis. Arch. Environ. Contam. Toxicol. 54, 504-515.

Incaper (Instituto Capixaba de Pesquisa), Sistema de Informações Metereológicas. 2018 Access in May $11^{\text {th }} 2018<$ https://meteorologia.incaper.es.gov.br/graficos-da-seriehistorica-vitoria>.

Instituto Chico Mendes de Conservação da Biodiversidade (ICMBio) Ministério do Meio Ambiente Brasil, 2018. Nota Técnica no. 23/2017/TAMAR-Vitoria-ES/DIBIO/ICMBio (Access on April 11 $1^{\text {th }}$ 2018. Disponible in). http://www.icmbio.gov.br/portal/images/stories/Rio_Doce/nota_tecnica_23_2017_Tamar_ICMBio_monitoramento_ pluma.pdf.

Jiang, C.B., Yeh, C.Y., Lee, H.C., Chen, M.J., Hung, F.Y., Fang, S.S., Chien, L.C., 2010. Mercury concentration in meconium and risk assessment of fish consumption among pregnant women in Taiwan. Sci. Total Environ. 408, 518-523.

Komárek, M., Ettler, V., Chrastný, V., Mihaljevič, M., 2008. Lead isotopes in environmental sciences: a review. Environ. Int. 34 (4), 562-577.

Kulkarni, R., Deobagkar, D., Zinjarde, S., 2018. Metals in mangrove ecosystems and associated biota: a global perspective. 2018. Ecotoxicol. Environ. Saf. 153, 215-228.

Laws, E.A., 1993. Aquatic Pollution (3rd). Wiley, New York.

Lewis, M., Pryor, R., Wilking, L., 2011. Fate and effects of anthropogenic chemicals in mangrove ecosystems: a review. Environ. Pollut. 159 (10), 2328-2346.

Lin, G., Sternberg, L.D.S., 1994. Utilization of surface water by red mangrove (Rhizophora mangle L.): an isotopic study. Bull. Mar. Sci. 54 (1), 94-102.

Luoma, S.N., Rainbow, P.S., 2008. Metal Contamination in Aquatic Environments: Science and Lateral Management. Cambridge University Press, Cambridge, p. 573.

Mattiuzzi, H.V., Marchioro, E., 2012. O Comportamento dos Ventos em Vitória (ES): a gestão e interpretação dos dados climatológicos. Rev. Geonorte 2 (4), 983-993.

McArthur, J.M., Howarth, R.J., Bailey, T.R., 2001. Strontium isotope stratigraphy: LOWESS version 3: best fit to the marine Sr-isotope curve for 0-509 ma and accompanying look-up table for deriving numerical age. J. Geol. 109 (2), 155-170.

McLusky, D.S., Elliott, M., 2004. The Estuarine Ecosystem; Ecology, Threats and Management. 3rd Edn. OUP, Oxford, p. 216.

Miranda, J.F., Mendoza-Carranza, M., Sánchez, A.J., Barba, E., 2017. Selective foraging of Aratus pisonii (Arthropoda: Sesarmidae) on mangrove leaves in laboratory experiments. J. Exp. Mar. Biol. Ecol. 488, 38-43.

Monferrán, M.V., Garnero, P., Bistoni, M.A., Anbar, A.A., Gordon, G.W., Wunderlin, D.A., 2016. From water to edible fish. Transfer of metals and metalloids in the San Roque Reservoir (Córdoba, Argentina). Implications associated with fish consumption. Ecol. Indic. 63, 48-60.

NASA - National Aeronautics and Space Administration, 2014. The Earth Observer. 26 (1). (48pp).

Négrel, P., Petelet-Giraud, E., 2012. Isotopic evidence of lead sources in Loire River sediment. Appl. Geochem. 27 (10), 2019-2030.
Négrel, P., Blessing, M., Millot, R., Petelet-Giraud, E., Innocent, C., 2012. Isotopic methods give clues about the origins of trace metals and organic pollutants in the environment. Trends Anal. Chem. 38, 143-153.

Negrel, P., Ollivier, P., Flehoc, C., Hube, D., 2017. An innovative application of stable isotopes $(\delta 2 \mathrm{H}$ and $\delta 180)$ for tracing pollutant plumes in groundwater. Sci. Total Environ. 578, 495-501.

Peterson, B.J., Fry, B., 1987. Stable isotopes in ecosystem studies. Annu. Rev. Ecol. Syst. 293-320.

Podio, N.S., Baroni, M.V., Badini, R.G., Inga, C.M., Ostera, H.A., Cagnoni, M., Gautier, E.A., García, P.P., Hoogewerff, J., Wunderlin, D.A., 2013. Elemental and isotopic fingerprint of Argentinean wheat. Matching soil, water and crop composition to differentiate provenance. J. Agric. Food Chem. 6, 3763-3773.

Potter, I.C., Chuwen, B.M., Hoeksema, S.D., Elliott, M., 2010. The concept of an estuary: a definition that incorporates systems which can become closed to the ocean and hypersaline. Estuar. Coast. Shelf Sci. 87, 497-500.

Rabelo, L.B., Muto, E.Y., Soares, L.S.H., 2009. Observações preliminares sobre o hábito alimentar do robalo-flecha Centropomus undecimalis (Bloch, 1792) e robalo-peba Centropomus parallelus (Poey, 1860) no estuário de Caravelas (Bahia-Brasil). Boletim Técnico Científico do CEPENE, Tamandaré 17 (1), 89-96.

Reed, W.R., Westman, E.C., 2005. A model for predicting the dispersion of dust from a haul truck. Int. J. Surf. Min. Reclam. Environ. 19 (1), 66-74.

Santos, J.M., Reis Jr., N.C., 2011. Caracterização e quantificação de partículas sedimentadas na região da Grande Vitória. Relatório Técnico Instituto Estadual do Meio Ambiente.

Santos, T.C., Carvalho, V.S.B., Reboita, M.S., 2016. Avaliação da influência das condições meteorológicas em dias com altas concentrações de material particulado na Região Metropolitana do Rio de Janeiro. Revista de Engenharia Sanitária e Ambiental 21 (2), 307-313.

Santos, J.M., Costa Reis, N., Silva Galvão, E., Silveira, A., Goulart, E.V., Lima, A.T., 2017. Source apportionment of settleable particles in an impacted urban and industrialized region in Brazil. Environ. Sci. Pollut. Res. 24, 22026-22039.

Souza, I.C., Duarte, I.D., Pimentel, N.Q., Rocha, L.D., Morozesk, M., Bonomo, M.M., Azevedo, V.C., Pereira, C.D.S., Monferrán, M.V., Milanez, C.R.D., Matsumoto, S.T., Wunderlin, D.A., Fernandes, M.N., 2013. Matching metal pollution with bioavailability, bioaccumulation and biomarkers response in fish (Centropomus parallelus) resident in neotropical estuaries. Environ. Pollut. 180, 136-144.

Souza, I, Bonomo, M.M. Morozesk, M. Rocha, L.D, Duarte, I.D, Furlan, L.M., Arrivabene, H.P., Monferrán, M.V., Matsumoto, S.T., Milanez, C.R.D., Wunderlin, D.A., Fernandes, M.N., 2014a. Adaptive plasticity of Laguncularia racemosa in response to different environmental conditions: integrating chemical and biological data by chemometrics. Ecotoxicology 23, 335-348.

Souza, I.C., Morozesk, M., Duarte, I.D., Bonomo, M.M., Rocha, L.D., Furlan, L.M., Arrivabene, H.P., Monferrán, M.V., Matsumoto, S.T., Milanez, C.R.D., Wunderlin, D.A., Fernandes, M.N., 2014b. Matching pollution with adaptive changes in mangrove plants by multivariate statistics. A case study, Rhizophora mangle from four neotropical mangroves in Brazil. Chemosphere 108, 115-124.

Souza, I.C., Rocha, L.D., Morozesk, M., Bonomo, M.M., Arrivabene, H.P., Duarte, I.D., Furlan, L.M., Monferrán, M.V., Matsumoto, S.T., Milanez, C.R.D., Wunderlin, D.A., Fernandes, M.N., 2015. Changes in bioaccumulation and translocation patterns between root and leaves of Avicennia schaueriana as adaptive response to different levels of metals in mangrove system. Mar. Pollut. Bull. 94, 176-184.

USEPA, 2009. Risk-based Concentration Table. Philadelphia PA, United States Environmental Protection Agency, Washington.

Wolanski, E., Elliott, M., 2015. Estuarine Ecohydrology: An Introduction. Elsevier, Whatham (322p)

Wunderlin, D.A., Díaz, M.P., Amé, M.V., Pesce, S.F., Hued, A.C., Bistoni, M.A., 2001. Pattern recognition techniques for the evaluation of spatial and temporal variations in water quality. A case study: Suquía River Basin (Córdoba - Argentina). Water Res. 35, 2881-2894.

Yeager, L.A., Stoner, E.W., Peters, J.R., Layman, C.A., 2016. A terrestrial-aquatic food web subsidy is potentially mediated by multiple predator effects on an arboreal crab. J. Exp. Mar. Biol. Ecol. 475, 73-79. 